\title{
Balk, Devanathan, Malliaras, Nagahara, and Torsi to chair 2015 MRS Fall Meeting
}

\author{
www.mrs.org/fall2015
}

$\mathrm{M}$ eeting chairs for the 2015 Materials Research Society (MRS) Fall Meeting are T. John Balk (University of Kentucky, USA), Ram Devanathan (Pacific Northwest National Laboratory, USA), George G. Malliaras (École Nationale Supérieure des Mines, France), Larry A. Nagahara (National Cancer Institute, USA), and Luisa Torsi (University of Bari “A. Moro," Italy). The meeting will be held November 29December 4, 2015, in Boston, Mass.

T. John Balk is an associate professor in the Department of Chemical and Materials Engineering at the University of Kentucky, where he has worked since 2004. He received his BS degree from the University of California-Berkeley, where he double-majored in mechanical engineering and materials science and engineering. He received his $\mathrm{MS}$ and $\mathrm{PhD}$ degrees in materials science and engineering from The Johns Hopkins University. He completed his postdoctoral work at the Max Planck Institute for Metals Research, where he was a staff scientist prior to joining the faculty at Kentucky.

His research focuses on structureproperty relationships in the mechanical behavior of metals, alloys, and covalent materials, primarily systems that allow the study of size effects. His current work is on the deformation mechanisms that operate in nanoporous noble metals and nanoporous silicon, and separately, the effects of thin-film microstructure on the work function of dispenser cathode materials.

Balk was awarded the Bradley Stoughton Award for Young Teachers from ASM International in 2007 and an NSF CAREER Award in 2008. $\mathrm{He}$ is faculty advisor to the Material Advantage student chapter at his university. He was chair of the 2012 Gordon Research Conference on Thin Film and Small-Scale Mechanical Behavior. He has organized three MRS symposia and served as a volume organizer in 2010 for

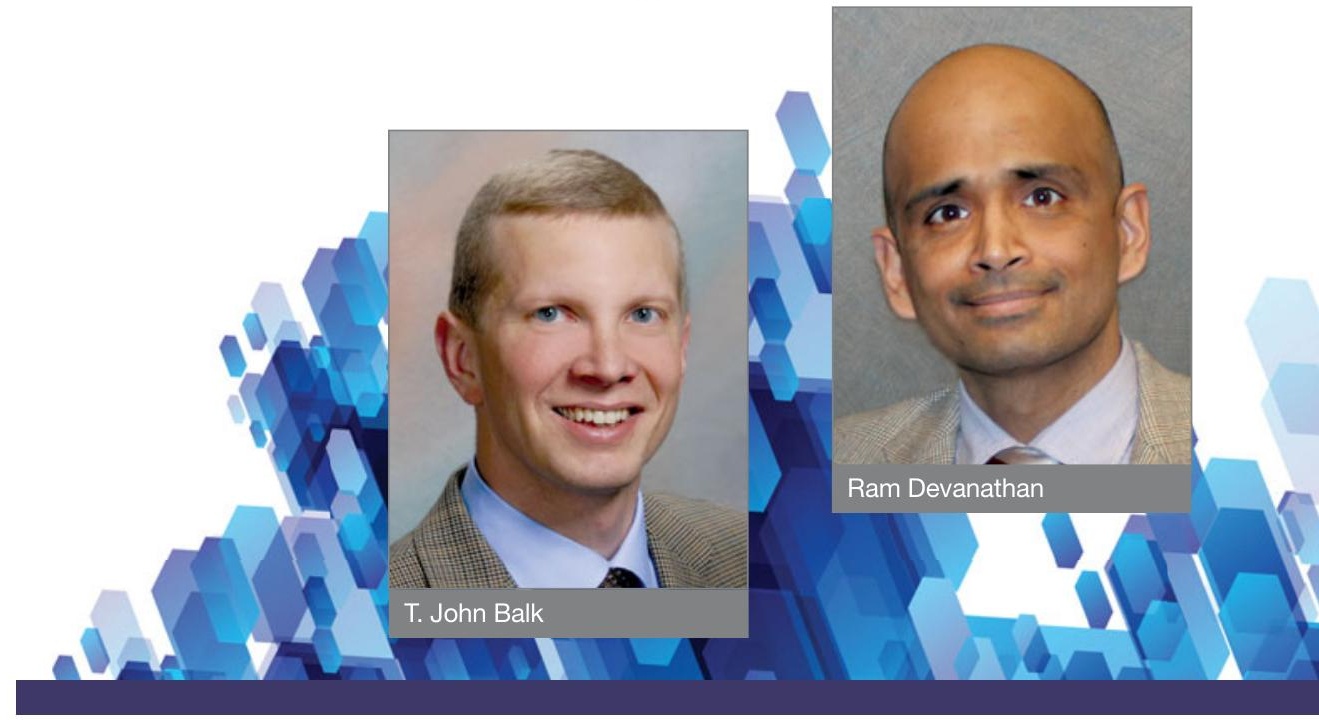

MRS Bulletin. Balk currently serves on the Society's Grassroots Subcommittee of the Government Affairs Committee and was part of the delegation to Congressional Visits Day in Washington, DC, in March 2013.

Ram Devanathan is a technical group manager in the Energy \& Environment Directorate at Pacific Northwest National Laboratory (PNNL), leading a group of 40 scientists and engineers in developing innovative materials science solutions to tackle energy and environmental challenges. He is also an adjunct professor in the School of Mechanical and Materials Engineering at Washington State University.

He received a BTech degree in metallurgical engineering from the Indian Institute of Technology Madras, a PhD degree in materials science and engineering from Northwestern University in 1993, and a MBA degree from Washington State University in 2011. Devanathan was a postdoctoral researcher at Los Alamos National Laboratory and PNNL; he then joined the Indian Institute of Technology Madras as an assistant professor of metallurgical engineering before returning to PNNL in 2003.

Devanathan's research interests include modeling and simulation of proton hopping in polymer electrolytes, selective molecular transport through graphene oxide membranes, design of ceramics for extreme environments, and materials informatics. He has published over 100 peer-reviewed papers. He is a recipient of the US Department of Energy's Outstanding Mentor Award in 2010 for his efforts to involve high school, undergraduate, and graduate students in computational materials science, and The American Ceramic Society's Richard M. Fulrath Award in 2012 for ceramics research.

George G. Malliaras is the head of the Department of Bioelectronics at the Centre Microélectronique de Provence of the École Nationale Supérieure des Mines de Saint-Étienne. He received a BS degree in physics from Aristotle University in 1991 and a $\mathrm{PhD}$ degree in mathematics and physical sciences from the University of Groningen in 1995.

After a two-year postdoctoral period at the IBM Almaden Research Center, he joined the faculty in the Department of Materials Science and Engineering at Cornell University. From 2006 to 2009, he served as the Lester B. Knight Director of the Cornell NanoScale Science \& Technology Facility prior to joining the Centre Microélectronique de Provence in 2009. 
